\title{
MODA E REPOSICIONAMENTO DE MARCAS POPULARES DE VESTUÁRIO E ACESSÓRIOS
}

\author{
Fashion and repositioning of apparel and accessories popular brands
}

Moda y reposicionamiento de marcas populares de vestuario y accesorios

\author{
Sarah Schmithausen Schmiegelow \\ Doutoranda em Design - \\ Universidade Federal de Santa Catarina \\ sarahschmiegelow@gmail.com \\ Richard Perassi Luiz de Sousa \\ Professor titular - \\ Universidade Federal de Santa Catarina \\ richard.perassi@uol.com.br
}

\section{Resumo}

Este artigo apresenta exemplos estratégicos do reposicionamento das marcas populares de vestuário e acessórios "C\&A", "Lojas Renner", "Marisa" e "Riachuelo", observados na atuação comercial e na comunicação de seus produtos. O termo posicionamento designa um conceito relacionado à necessidade de parâmetros para a atuação da marca no mercado, sendo percebido em comparação com a comunicação pública das outras marcas. Analisando o posicionamento das marcas populares de vestuário, observa-se que permanecem os argumentos baseados em "qualidade e preço", mas esses são apresentados em constante e enfática associação da marca ao conceito de Moda. Como resultado, é evidenciado que houve o fechamento de um ciclo na relação entre o conceito de "Moda" e o posicionamento de mercado das marcas populares deste segmento, resultando na retomada da plena identificação publicitária entre Moda e produtos de vestuário e acessórios.

Palavras-chave: Comunicação da Marca. Cultura de Mercado. Produtos de Moda.

\begin{abstract}
This paper presents strategic examples of brand repositioning of the popular apparel and accessories brands "C\&A", "Lojas Renner", "Marisa" e "Riachuelo", observed at the commercial interaction and products communication. Brand positioning is a concept related to the necessity of parameters for the brand performance, perceived in comparison with the others brands public communication. Analyzing the popular apparel brands positioning, we observe that the arguments based on "quality and price" remain, but these are presented with the constant and emphatic association of the brand with the fashion concept. As result, we evidenced that a cycle was closed in the relation between the concept of "Fashion" and the market positioning of the popular brands of this segment, resulting in the resumption of the full advertising identification between Fashion and clothing and accessories products.
\end{abstract}

Key words: Brand communication. Market culture. Fashion products. 


\section{Resumen}

Este artículo presenta ejemplos estratégicos del reposicionamiento de las marcas populares de vestuario y accesorios "C\&A", "Lojas Renner", "Marisa" y "Riachuelo", observados en la actuación comercial y en la comunicación de sus productos. El término posicionamiento designa un concepto relacionado a la necesidad de parámetros para la actuación de la marca en el mercado, siendo percibido en comparación con la comunicación pública de las otras marcas. Analizando el posicionamiento de las marcas populares de vestuario, se observa que permanecen los argumentos basados en "calidad y precio", pero estos son presentados en constante y enfática asociación de la marca con el concepto de Moda. Como resultado, se evidenció que hubo el cierre de un ciclo en la relación entre el concepto de "Moda" y el posicionamiento de mercado de las marcas populares de este segmento, resultando en la reanudación de la plena identificación publicitaria entre Moda y productos de vestuario y accesorios.

Palabras clave: Comunicación de la marca. Cultura de Mercado. Productos de Moda.

\section{INTRODUÇÃO}

Inseridas na cultura, as marcas extraem seus significados e também participam como mediadoras da significação simbólico-cultural no contexto em que se originam e desenvolvem (BATEY, 2010). Nessa participação, é constituída e desenvolvida a "imagem da marca", como acervo significativo que associa sentimentos e ideias ao sinal percebido como marca (RUÃO; FARHANGMER, 2000; PERASSI, 2001).

Como sinal simbólico, a marca é a síntese expressiva e significativa que identifica, distingue e representa um amplo sistema cultural aberto e interativo, porque a cultura particular de cada marca emerge e interage na cultura de mercado e no contexto da cultura em geral (PERASSI, 2001). A interação propicia que as renovações culturais repercutam na cultura de mercado e na cultura das marcas.

A marca perceptível é expressiva, dispondo de atributos próprios e representando valores específicos, que são distintivos em relação a outras marcas. Isso constitui a identidade da marca e garante sua unidade, como sistema cultural aberto e interativo. Por ser aberto, o sistema cultural da marca também é dinâmico, porque há aspectos que evoluem ou são substituídos mediante influência do meio cultural. Mas, a identidade da marca ainda permanece se as mudanças ocorrerem parcialmente e em diferentes períodos de tempo.

A manutenção de sua identidade, durante o processo evolutivo, permite que a marca resista aos impactos culturais e possibilita estratégias e ações de gestão. Isso propõe o aprimoramento ou o reposicionamento da marca, diante das mudanças da cultura de mercado 
ou da cultura em geral. Assim, mudanças socioeconômicas, questões ambientais, movimentos ideológicos ou modismos podem impactar o sistema cultural da marca, provocando ou requerendo sua mudança ou mesmo reposicionamento.

Uma marca cuja expressão não vai ao encontro do que os consumidores anseiam perde espaço no mercado, porque deixa de ser valorizada. Portanto, as renovações dos valores, desejos e necessidades do público devem ser monitoradas e incorporadas ao processo de gestão da marca que, assim, atualiza sua promessa de valor e sua imagem positiva na cultura de mercado. O posicionamento ou o reposicionamento da marca deve manter a identidade, mas precisa ser proposto em resposta às especificidades do mercado e à posição dos competidores em uma determinada época (KAPFERER, 2008).

Tradicionalmente, sem desconsiderar a necessidade de os consumidores estarem socialmente apresentáveis com suas vestimentas, o posicionamento (hard sell) das marcas populares no comércio de vestuário e acessórios enfatizava a relação favorável entre o custo acessível e as qualidades materiais dos produtos. Isso contrasta com as grifes de vestuário e acessórios, cujo posicionamento (soft sell) enfatiza um conjunto de valores intangíveis, implicando em conceitos como: elegância, exclusividade, luxo, status e, especialmente, Moda.

Atualmente, por meio de estratégias e discursos publicitários específicos, algumas marcas populares deste segmento demarcam individualmente seu reposicionamento na cultura de mercado como marcas de Moda. Apesar das particularidades, observa-se que, de maneira geral, vem ocorrendo a associação dos discursos das marcas populares ao universo simbólico de Moda.

Este artigo trata da associação simbólico-cultural entre o conceito "Moda" e a oferta comercial de produtos de vestuário e acessórios de marcas populares, considerando-se que a comunicação pública dessa associação configura um reposicionamento de marca. Como objeto de estudo, foram observadas as estratégias de comunicação das marcas populares de vestuário "C\&A", "Lojas Renner", "Marisa" e "Riachuelo". Quanto aos procedimentos metodológicos, é um estudo de caráter teórico, natureza qualitativa, objetivos exploratórios, e procedimentos técnicos de pesquisa bibliográfica e documental. O estudo evidencia que o reposicionamento destas marcas populares como marcas de Moda caracterizou o fechamento de um ciclo, retomando a plena identificação publicitária entre Moda e produtos de vestuário e acessórios. 


\section{COMPOSIÇÃO E COMUNICAÇÃO DO POSICIONAMENTO DA MARCA}

Seguindo a tradicional conceituação de marca proposta pela American Marketing Association, Perassi $(2001 ; 2015)$ adverte que, em sentido restrito, a marca é um sinal ou conjunto de sinais que serve como elemento de identificação e distinção, atuando como signo ou símbolo, porque representa pessoa, produto, serviço ou organização, e também significa tudo que é associado à entidade representada.

A palavra sinal indica algo expressivo, ou seja, aquilo que é percebido por sentidos e sensores (PERASSI, 2015). Contudo, ao ser mentalmente associado com lembranças de objetos, fatos, ideias ou sentimentos um sinal ou um conjunto de sinais é percebido e lido como signo, porque expressa e representa outras coisas além de sua própria existência (PEIRCE, 2007). Portanto, a significação é decorrente da associação, porque um sinal é "significante" quando associado à lembrança de outra coisa mental ou material que passa a ser seu "significado" (SAUSSURE, 2002).

Todo signo ou símbolo percebido é marca do acervo das coisas que representa. Por exemplo, uma peça de vestuário pode ser marca de vestimenta, pudor, costura, comércio ou cultura. Sob alguns aspectos, também pode ser marca de Moda, porque já é tradicional a ligação entre Moda e vestuário. Devido a essa significação indistinta em grande parte das peças, o fabricante e o comerciante de vestuário necessitam marcar o que produzem ou vendem, com um nome ou outro sinal, para identificar e distinguir seus produtos dos concorrentes.

Além de identificar e distinguir os produtos e seus atributos, a marca também passa a representá-los publicamente. Para o público que percebe o nome ou outro símbolo de identificação, a organização, os produtos, os serviços, os atributos, as experiências, as ideias e os sentimentos que a marca distingue também são rememorados na representação.

Por isso, na cultura de mercado, marca é um sinal ou conjunto de sinais cuja expressão simboliza sinteticamente o acervo memorativo de sensações, sentimentos e ideias que, ao longo do tempo, foram associados com a organização e seus produtos, serviços e atributos. Ao ser associado às expressões da marca pelo público, seja individualmente ou coletivamente, o acervo memorativo constitui a imagem da marca.

Juntamente com Kapferer (2008), considera-se que a "identidade da marca" é proposta pelo emissor, sendo diretamente relacionada à autoimagem. Publicamente, a identidade é representada e comunicada em tudo que pode ser percebido e associado à marca. Por sua vez, 
a imagem da marca, como síntese mental, resulta do contato assistemático do público com tudo que é associado à marca, sejam expressões oficiais ou manifestações informais. A imagem da marca é mais imprevisível, porque depende das vivências particulares e da troca de informações e influências entre os consumidores (PERASSI, 2015).

A construção e a evolução da marca ocorrem de maneira interativa entre o que é comunicado pela organização emissora da marca (input) e o que é percebido (output) e retransmitido pelo público de volta para o conhecimento da organização (feedback). Inclusive, atualmente, não se propõe posicionamento ou reposicionamento da marca sem prévio estudo das condições do mercado.

O processo de gestão da marca (Branding) busca o controle possível sobre todas as manifestações públicas que podem ser associadas à marca. Isso requer o mapeamento detalhado e o controle eficiente dos "pontos de contato" entre as manifestações da marca e o público.

Para haver gerenciamento e controle é necessário o estabelecimento de parâmetros, porque isso permite a percepção sobre o que está sendo devidamente gerenciado e o que corre o risco de sair do controle. O conhecimento e a configuração da identidade da marca estabelecem um parâmetro para a atuação do negócio e a comunicação da marca.

A maneira como são realizadas as manifestações e as atuações públicas associadas à marca, incluindo o próprio sistema de identidade gráfica, comunica sua identidade e estabelece o posicionamento da marca na cultura de mercado. O posicionamento é proposto e percebido em comparação com a comunicação pública das outras marcas.

De acordo com as características e possibilidades da identidade, em relação às condições culturais e econômicas do mercado, a definição prévia e coerente do posicionamento da marca orienta todo o sistema de informação e comunicação da marca. Portanto, o posicionamento é necessário para qualificar a comunicação da marca, evitando confundir ainda mais o público consumidor, que já está exposto ao excesso de informações. Atualmente, o posicionamento não se refere apenas ao consumo funcional de produtos ou serviços, porque a marca deve assumir um status afetivo-simbólico no já constituído acervo imaginário dos consumidores (RIES; TROUT, 2009).

Para Kapferer (2008), posicionar uma marca significa enfatizar suas características distintivas, que são também atraentes ao público. As escolhas dos consumidores são feitas por comparação entre os produtos das diferentes marcas. Portanto, o posicionamento é orientado pela competição e pode mudar com o tempo. Um posicionamento de marca deriva de sua 
identidade e, enquanto prevalece, enfatiza algumas características, de acordo com as condições do mercado, dos consumidores e dos concorrentes.

Todas as mensagens dirigidas ao mercado devem anunciar e ser coerentes com a identidade e o posicionamento de marca. O parâmetro básico da gestão e da comunicação de marca é, portanto, manter a equivalência possível entre a "identidade da marca" e a "imagem da marca", sendo que o sucesso é evidenciado se a imagem pública for mais positiva que a identidade da marca.

Diante das dificuldades em gerenciar a resposta perceptiva do público, o processo de criação, desenvolvimento e gestão da marca é predominantemente realizado por estímulos comunicativos positivos. Por isso, Bonsiepe (2011) ressalta que Branding está relacionado à comunicação, para predispor o público a avaliar positivamente a marca. O objetivo é obter o melhor controle possível sobre a recepção do público com relação à marca. Portanto, a gestão da marca é baseada no gerenciamento possível de sua comunicação (PERASSI, 2015).

\section{O REPOSICIONAMENTO DAS MARCAS NO MERCADO DE VESTUÁRIO}

Por meio de seus produtos e serviços de comunicação e atuação, as marcas se posicionam no mercado como detentoras de uma oferta específica, cujos valores estéticosimbólicos, expressos em seus produtos e serviços, estão à disposição dos consumidores. Isso propõe recursos aos consumidores para que possam compor, incrementar e publicar a sua própria identidade de marca. Tradicionalmente, algumas marcas de comércio propõem o apelo de Moda como sendo a principal característica estético-simbólica de seu posicionamento na cultura de mercado. Além dessas, outras marcas têm alterado sua posição para associar seu nome e sua cultura ao conceito de Moda, sendo que essa associação também é constantemente requerida na própria marca pessoal dos consumidores.

As marcas C\&A, Lojas Renner, Marisa e Riachuelo destacam-se entre outras marcas populares do comércio de produtos de vestuário como grandes redes atuantes em todo o território nacional. Tradicionalmente, a comunicação dessas marcas ressalta a oferta de produtos de vestuários industrializados, de boa qualidade e com preços acessíveis. As lojas dessas marcas são âncoras na oferta comercial de shopping centers do país. Mas apesar de seu posicionamento já consolidado, há alguns anos, de maneira sutil e continuada, a comunicação dessas marcas busca associar-se e incorporar em sua cultura o conceito de Moda. 
Pelo menos parcialmente, isso é explicado pelo hiperconsumo, que como explica Lipovestky (2007), é caracterizado por consumidores imprevisíveis e voláteis, que anseiam por mais qualidade de vida, saúde e comunicação, e são mais qualificados para escolher entre as diversas ofertas. Em especial, o hiperconsumo caracteriza uma nova relação das classes populares e médias com o luxo e as marcas de qualidade, anteriormente inacessíveis a estes grupos. Estes vivenciaram uma democratização do conforto, do lazer e dos prazeres quando a tradicional oposição entre o consumo de necessidades pelas classes populares e o consumo de luxo pelas classes ricas foi abalada (LIPOVETSKY, 2007).

Appel (2012) complementa que o conceito de Moda, anteriormente relacionado às classes altas, atualmente é consumido em diferentes estratos sociais. Com relação à economia nacional, Schettino e Maia (2014) consideram que na última década foi possível observar uma nova classe trabalhadora com acesso ao consumo e à informação. A classe $\mathrm{C}$ brasileira passou por um movimento de ascensão social, com mudanças nos hábitos de consumo e maior acesso à informação (SCALFI; BARRIZZELLI, 2012). Isso aumentou o interesse por crenças e valores sociais, incluindo os diretamente associados à cultura de Moda.

Atualmente, a exposição do público consumidor das classes populares aos símbolos de Moda desperta desejos e estimula a busca por significados. Para Messias (2012), isso repercutiu na comunicação das marcas C\&A, Riachuelo e Renner, que são as três maiores redes de lojas populares de comércio de produtos de vestuário no Brasil. Atualmente, o preço acessível e a associação com Moda caracterizam a comunicação dessas marcas (MESSIAS, 2012).

Caetano (2013) considera que, em sua atuação, essas e outras marcas adotam a estratégia denominada fast fashion (moda rápida), fazendo que os produtos de Moda sejam oferecidos nos pontos de venda no exato momento em que uma tendência assume o mercado. As marcas Zara (Espanha) e H\&M (Suécia) representam redes internacionais de lojas fast fashion. O modelo de negócio requer a atualização mensal das tendências de Moda, sendo que algumas redes podem comercializar cerca de 20 diferentes coleções por ano (WATSON; YAN, 2013).

Para Franke (2011), a constatação de que as peças são vendidas em série nas lojas não impede que as mesmas sejam associadas pelo público à cultura de Moda. Primeiramente, porque a possibilidade associativa foi desenvolvida de modo gradual, através de um processo pelo qual o conceito Moda foi atribuído aos produtos, inserindo-os no sistema de Moda. A associação entre Moda e marcas populares de vestuário é parte da gestão da comunicação da 
marca, porque a publicação significativa da cultura de cada marca depende diretamente de publicidade e de todas as manifestações públicas da marca, as quais devem ser bem gerenciadas, mediadas e comunicadas.

Uma estratégia de comunicação usada por esta categoria de marcas é apresentada por Caetano (2013) como cross branding ou co-branding, consistindo em unir marcas na promoção de um produto ou serviço, sendo que isso possibilita que, reciprocamente, a reputação de uma marca endosse a outra. Assim, estilistas renomados e publicamente associados à cultura de Moda foram contratados para produzirem coleções de vestuários e acessórios para serem exclusivamente comercializadas nas lojas da marca contratante. De maneira semelhante, outros profissionais publicamente associados com Moda, como artistas e modelos famosos, também são contratados e associados às marcas populares de vestuário.

Além da associação com o trabalho e a pessoa de profissionais famosos, outros ícones visuais relacionados à cultura de Moda também são incorporados na comunicação publicitária da marca. Assim, além das próprias peças de roupa e acessórios, que já são associadas à cultura de Moda, também há a contratação de modelos e o uso de imagens que representam poses e cenários típicos das produções de Moda.

Messias (2012) confirma o comércio de coleções exclusivas assinadas por estilistas renomados como prática comum nas lojas das marcas Riachuelo e C\&A. A convivência e a aquisição de produtos acessíveis, assinados pelos mesmos estilistas associados às marcas de luxo, sugerem aos consumidores das lojas fast fashion a familiaridade desejada com o universo simbólico e luxuoso de Moda (CONTINO; CIPINUIK, 2014).

Acerca do processo de reposicionamento, a marca holandesa C\&A, que iniciou o comércio de produtos no Brasil na década de 1970, primeiramente se posicionou com a oferta de roupas e acessórios de qualidade e bom preço. Motivada pela impossibilidade da rede se estabelecer como uma referência ao público de classe média, a marca passou por revisão das estratégias de posicionamento no final da década de 1990. A partir desse momento, os esforços foram voltados a desvincular a marca dos conceitos de popular e barato, projetando uma imagem fashion e sofisticada (TELLES, 2004).

Por sua vez, o grupo representado pela marca Renner foi fundado em 1912, sendo que em 1940 a marca passou a representar uma rede nacional de lojas de departamentos, que prosperou e se destacou nacionalmente. Em 1991, o negócio foi reestruturado para atuar como uma rede de lojas de departamentos de vestuário e acessórios especializada em produtos de Moda. 
Publicamente, a associação do nome Renner ao conceito de Moda ocorreu através do apoio a eventos do setor, incluindo ainda a apresentação de coleções exclusivas da marca (FRANKE, 2011). Porém, as outras marcas próprias do negócio Renner buscam desenvolver e atender os consumidores com peças de vestuário em diferentes estilos. A ideia de que os consumidores buscam desenvolver sua identidade e comunicar sua marca, cabendo ao fornecedor de Moda oferecer-lhes recursos para isso, é claramente aceita no posicionamento da marca Renner. Isso é ilustrado no slogan "você tem seu estilo, a Renner tem todos".

Outra marca do segmento que passou por mudanças similares é a empresa Marisa. Suas lojas iniciaram com a venda de bolsas em 1984, passando em seguida a oferecer roupas de qualidade e preço atrativo. Atualmente, a marca Marisa se descreve como focada na oferta para a classe $\mathrm{C}$ de produtos de qualidade e de acordo com as últimas tendências de Moda (MARISA, 2015).

A trajetória da rede de lojas Riachuelo exemplifica bem o reposicionamento de Moda de uma marca popular de vestuário. De acordo com informações disponíveis no website oficial da marca, em 1947 a empresa Riachuelo iniciou suas atividades de venda de tecidos a preços baixos, sendo que o comércio de roupas prontas teve início em 1979, quando a empresa foi comprada pelo grupo Guararapes. Schettino e Maia (2014) afirmam que, depois de sua incorporação, o posicionamento da marca foi caracterizado pela oferta de vestimentas básicas. Foi na década de 1990 que os negócios da marca foram direcionados à oferta de produtos de Moda a preços acessíveis (FRANKE, 2011; SCHETTINO; MAIA, 2014).

Trata-se, entretanto, de considerar qual o tipo de relação foi primeiramente estabelecido entre a marca Riachuelo e o conceito de Moda. Como foi proposto anteriormente, de modo geral, as peças de vestuário são comumente relacionadas à cultura de Moda. Todavia, no mercado popular brasileiro dos anos 1990, a cultura de Moda era inserida no cotidiano das pessoas de maneira menos complexa e influente que na atualidade. Portanto, considera-se que, primeiramente, essa relação era basicamente decorrente do tipo de negócio. Anteriormente, a ideia de Moda fazia parte do negócio, mas, atualmente, o negócio é todo e diretamente direcionado à cultura de Moda.

Isso explica que, ao estudar as estratégias do grupo Guararapes para a loja Riachuelo, na década de 1990, Silva (2011) considera que essas eram menos focadas em Moda e diretamente relacionadas ao alto volume de vendas decorrente das vantagens de qualidade e preço dos produtos industrializados. Portanto, o processo de reposicionamento da marca é um fenômeno mercadológico que vem evoluindo nas décadas posteriores ao ano 2000. Tal 
fenômeno é observado em interação com a ampliação do acesso ao consumo pelas classes populares.

A partir dos anos 2000, houve a revisão das estratégias de posicionamento das marcas com base na segmentação tradicional por renda, idade ou localização, entre outras. Assim, a oferta dos produtos comercializados pela marca Riachuelo passou a ser proposta com forte apelo às tendências e estilos de Moda. Isso pretende atingir os consumidores das classes populares que passaram a se interessar e pagar por produtos de Moda (SILVA, 2011). Para Cruz-Moreira (2003), a marca Riachuelo foi revalorizada, porque deixou de ser um canal de escoamento de produtos do grupo Guararapes para ser uma rede fast fashion com 280 lojas brasileiras que, com sua influência, atribui valor de Moda aos produtos, os quais são constantemente renovados de acordo com as tendências vigentes.

Uma estratégia de reposicionamento da marca Riachuelo foi a inauguração em 2013 da loja-conceito na rua Oscar Freire, localizada no bairro de Jardins, região nobre da cidade de São Paulo. Com essa iniciativa, a empresa inseriu sua marca em local que é reconhecido pela ocupação de lojas de grifes nacionais e internacionais de Moda. Em seu website oficial, a comunicação da marca informa que essa iniciativa "dá continuidade ao processo de democratização da moda".

A recente e radical transformação da marca gráfica Riachuelo (Fig. 1B) assinala o ápice do processo de reposicionamento da marca em associação ao conceito de Moda. A marca gráfica anterior é composta por logotipo e monograma nas cores institucionais verde e azul. O logotipo apresenta por completo o nome "Riachuelo", em letras verdes e minúsculas, e o monograma apresenta uma estilização da letra "R" maiúscula em cor azul (Fig.1A).

Apesar de composta por um conjunto de letras e proposta como marca gráfica Riachuelo, a sigla é praticamente impronunciável como palavra. Também é muito extensa para ser soletrada. Portanto, considera-se que o conjunto de letras foi composto e proposto para atuar predominantemente como ícone gráfico-visual associado ao nome da marca. $\mathrm{O}$ rigor minimalista dos formatos tipográficos e o hermetismo da sigla sugerem sentidos de sofisticação e transcendência à marca. Além disso, essa ousadia pouco comum na representação da marca não deixa de ser uma "invenção de Moda". 
Figura 1: (A) marca gráfica Riachuelo (versão anterior); (B) marca gráfica Riachuelo (versão atual).

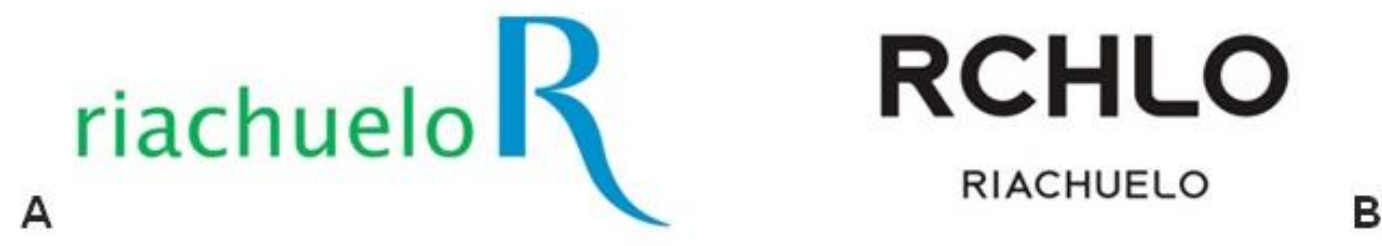

Fonte: http://www.riachuelo.com.br/.

\section{RESULTADOS E CONSIDERAÇÕES FINAIS}

A partir da observação das estratégias de reposicionamento das marcas "C\&A", "Lojas Renner", "Marisa" e "Riachuelo", o que foi apresentado neste artigo serve para evidenciar o fechamento de um ciclo na relação entre o conceito de "Moda" e o posicionamento na cultura de mercado das marcas de comércio de produtos de vestuário e acessórios. O ciclo é especialmente demarcado em quatro partes e seu fechamento resulta na retomada, pelo senso comum, da plena identificação publicitária entre Moda e produtos de vestuário e acessórios. Isso é decorrente da popularização de sinais, códigos e discursos que, por um período restrito de tempo, distinguiram as grifes de Moda de outros fornecedores de produtos de vestuário e acessórios.

1. Primeiramente, no senso comum, houve fortemente e permaneceu, ainda que de maneira enfraquecida, a tradicional associação entre vestuário, acessórios e "Moda". Isso ainda ocorre, apesar da palavra "Moda" representar um fenômeno social abrangente que, de maneira ampla e diversificada, afeta inúmeros aspectos da vida coletiva. Mas, ainda é comum que, primeiramente, as pessoas recuperem lembranças de produtos de vestuário e acessórios ao ouvirem a palavra "Moda";

2. Posteriormente, o senso comum foi influenciado ao reconhecimento, praticamente consensual, de que a palavra "Moda" não poderia adjetivar indiscriminadamente toda e qualquer peça de vestuário ou acessório porque para estar em Moda ou ser um produto de Moda a roupa ou o acessório deveria dispor de qualidades produzidas, percebidas e endossadas por profissionais autorizados pelo contexto econômico-político da cultura de Moda. Portanto, a associação de um produto ou serviço ao conceito de "Moda" passou a ter valor positivo de distinção e superioridade que, inclusive, justifica preços mais elevados;

3. Em seguida, os gestores das marcas populares de comércio de vestuário e acessórios buscaram reposicioná-las, devido à percepção pública distintiva do valor da associação ao 
conceito de "Moda". Para tanto, foram auxiliados pela tradicional relação do senso comum, já estabelecida e parcialmente enfraquecida, entre o conceito de "Moda" e produtos de vestuário e acessórios. Mas, além disso, foram planejadas estratégias e desenvolvidas ações para confirmarem o vínculo entre "Moda", vestuário e acessórios. Assim, foram contratados estilistas de renome popular, modelos, artistas e outros profissionais para produzirem ou participarem de produções configuradas e publicadas com recursos e códigos específicos de Moda e em associação direta com as marcas populares;

4. Enfim, completa-se o ciclo quando a relação entre o conceito de "Moda" e as marcas populares de produtos de vestuário e acessórios se torna comum. O ciclo é completo porque retorna-se ao estágio inicial em que no senso comum ocorre a plena identificação entre: vestuário, acessórios e "Moda". Doravante, a associação publicitária ao conceito de "Moda" por parte das marcas populares do comércio de produtos de vestuário e acessórios pode ser necessária, mas deixa de ser fortemente significativa. A preferência do público em função da percepção diferenciada de qualidade e posicionamento cultural na comunicação e na atuação das marcas continuará acontecendo. Mas, isso é decorrência de diferentes sinais que são observados e significativamente considerados, já que os discursos de Moda se tornaram básicos na comunicação das marcas populares de vestuário e acessórios.

$\mathrm{Na}$ comunicação das marcas populares, as estratégias de associação ao conceito de "Moda" são realizadas por conjuntos de ações estratégicas que reúnem e registram cores, formatos, objetos e pessoas, para expressarem, além de produtos e ambientes, também atitudes e posicionamentos publicamente reconhecidos como códigos de Moda. Isso é repercutido em diferentes meios de comunicação e centralizado de maneira comunicativa e interativa nos websites oficiais das marcas que são acessíveis na rede Internet.

A atuação gerencial e comercial das redes de lojas das marcas populares é igualmente adaptada aos interesses associativos da marca, por exemplo, adotando o modelo comercial fast fashion, com constante renovação de produtos de vestuário e acessórios, e também com a prática de cross branding ou co-branding, em parceria com estilistas renomados, cuja marca profissional já foi previamente associada com grifes de Moda. Investe-se, ainda, em apoiar eventos e participar de desfiles de Moda, com coleções de marcas exclusivas, além da possibilidade de instalação e manutenção de lojas conceituais em locais estratégicos com relação à cultura de Moda.

Em resumo, com estratégias de gestão e ações específicas, comerciais, comunicativas ou promocionais, algumas marcas populares do comércio de produtos de vestuário e 
acessórios posicionaram-se com sucesso na cultura de mercado em associação ao conceito de Moda. Isso possibilitou um posicionamento coerente com os desejos de consumo simbólico das classes populares emergentes na cena econômica brasileira.

O sucesso das iniciativas provocou, entretanto, a consolidação de um duplo vínculo pernicioso. Ao mesmo tempo em que o conceito de Moda foi eficientemente ou coerentemente associado a algumas marcas populares de vestuário e acessórios, no senso comum, também foi reforçada e destacada a relação já tradicional entre a ideia de Moda e os produtos de vestuário e acessórios, incluindo os mais populares. Isso sugere um impacto negativo, já que o conceito de Moda se torna comum, deixando de ser um valor distintivo para marcas populares deste segmento.

\section{APOIO}

O presente trabalho foi realizado com apoio da Coordenação de Aperfeiçoamento de Pessoal de Nível Superior - Brasil (CAPES) - Código de Financiamento 001.

\section{REFERÊNCIAS}

APPEL, P. B. Consumindo moda, estilos e individualidades: um estudo etnográfico das práticas de consumo de moda em grupos populares. 2009. Dissertação (Mestrado em Ciências Sociais) -

PUC/RS, Porto Alegre, RS, 2012.

BATEY, M. O significado da marca. Rio de Janeiro: Best Business, 2010.

CAETANO, C. C. O cross-branding e a cocriação no âmbito do varejo de moda. São Paulo, 2013. Dissertação (Mestrado em Ciências) - Programa de Pós-graduação em Têxtil e Moda da Escola de Artes, Ciências e Humanidades da Universidade de São Paulo, 2013.

CONTINO, J.; CIPINUIK, A. As coleções assinadas para redes de fast fashion e o seu valor simbólico. Iara: Revista de Moda Cultura e Arte, v.7, n.2, 2014. pp. 32-50.

CRUZ-MOREIRA, J. R. Industrial Upgrading nas cadeias produtivas globais: reflexões a partir das indústrias têxtil e do vestuário de Honduras e do Brasil. São Paulo, 2003. Tese (Doutorado em Engenharia), Escola politécnica da Universidade de São Paulo. Departamento de Engenharia de Produção, São Paulo, 2003.

FRANKE, G. A moda e o vestir sobre a perspectiva do popular: um estudo sobre o comportamento e a percepção de consumidores de um shopping popular sobre moda e consumo de vestuário. 2011. Dissertação (Mestrado em Sociologia) - UFRGS, Porto Alegre, RS, 2011. 
KAPFERER, J. N. The new strategic brand management: creating and sustaining brand equity long term. London and Philadelphia: Kogan Page, 2008.

KOTLER, P.; KELLER, K. L. Administração de Marketing. São Paulo: Pearson Education do Brasil, 2012.

KOTLER, P. Administração de marketing. 12 ed. Prentice Hall, 2006.

LIPOVETSKY, G. A felicidade paradoxal: ensaio sobre a sociedade de hiperconsumo. São Paulo: Companhia das letras, 2007.

MARISA. Histórico e perfil corporativo. Disponível em:

<http://ri.marisa.com.br/marisa/web/default_pt.asp?idioma=0\&conta=28\#>. Acesso em: 20 nov 2015.

MESSIAS, E. M. As lojas populares e a comercialização da elegância. In: II Seminário Internacional de Pesquisa: Consumo, Afetividades e Vínculos - A cidade, o lugar, o produto, 2012, São Paulo.

Anais do SIEP, 2012.

PERASSI, R. A Visualidade das Marcas Institucionais e Comerciais como Campo de Significação. 2001. Tese (Doutorado em Comunicação e Semiótica) - São Paulo: PUC/SP, 2001.

PERASSI, R. L. S. Comunicação e Conhecimento da marca das organizações. Texto didático. Florianópolis, EGC/UFSC, 2015.

PEIRCE, C. S. Semiótica. São Paulo: Perspectiva, 2007.

RIACHUELO. Empresa. Disponível em: $<$ http://www.riachuelo.com.br/a-riachuelo/empresa $>$. Acesso em: 20 nov 2015.

RIES, A.; TROUT, J. Posicionamento: a batalha por sua mente. São Paulo: M. Books do Brasil, 2009.

RUÃO, T. e FARHANGMER, M. A imagem da marca: análise das funções de representação e apelo no marketing das marcas. Um estudo de caso. Actas do I Seminário de Marketing Estratégico e Planeamento, Escola de Economia e Gestão, Universidade do Minho, 2000.

SAUSSURE, F. Escritos de linguística Geral. São Paulo: Cultrix, 2002.

SCHETTINO, P. B. C.; MAIA, F. J. S. Análise do posicionamento da marca Riachuelo: a democratização da moda como perspectiva de comunicação e marketing. In: XII Congreso Latinoamericano de Investigadores de la Comunicación - ALAIC 2014, p. 1-15.

TELLES, R. Posicionamento e reposicionamento de marca: uma perspectiva estratégica e operacional dos desafios e riscos. 2004. 204 f. Tese (Doutorado em Administração) - Faculdade de Economia, Administração e Contabilidade, Universidade de São Paulo, São Paulo, 2004.

WATSON, M. Z.; YAN, R. An exploratory study of the decision processes of fast versus slow fashion consumers. Journal of Fashion Marketing and Management, v.17, n.2, 2013. pp. 141-159. Disponível em: <http://dx.doi.org/10.1108/JFMM-02-2011-0045>. Acesso em: 21 nov 2015. 
Mestra em Engenharia e Gestão do Conhecimento - UFSC. Doutoranda no programa Pós-Design da Universidade Federal de Santa Catarina.

\section{Richard Perassi Luiz de Sousa}

Doutor em Comunicação e Semiótica - PUC/SP. Professor titular da Universidade

Federal de Santa Catarina, atua nos programas de pós-graduação em Design e Engenharia e Gestão do Conhecimento, e no programa de graduação em Design.

\section{@(๑)}

Esta obra está licenciado com uma Licença

Creative Commons Atribuição-NãoComercial-CompartilhaIgual 4.0 Internacional 